\title{
The Use of an Unconventional Construction Material for Affordable Housing in India
}

\author{
Chandra Sabnani
}

\begin{abstract}
Rapid growth in Urbanization has led to the creation of sections within the society with limited means, pushed into a life long struggle for survival. In such a scenario, even the basic needs are not possible to be met with. Large scale houselessness in urban areas results from the authorities turning a blind eye to the phenomenon and exploring possibilities of providing cheaper houses to the urban poor. It could start with the acceptance of the reality that conventional materials for construction of houses have failed to provide affordable housing for the urban poor, hence unconventional materials and techniques need to be researched upon.
\end{abstract}

Keywords- Affordable housing, bamboo, housing policy, unconventional materials

\section{INTRODUCTION}

$\mathrm{A}$ LARGE section of the society in Urban India is unable to afford a basic dwelling unit. Housing shortage due to the rising unaffordability makes it logical to consider alternative technologies more seriously for their application How far do these alternative technologies match up with the conventional techniques? How do these integrate with the present-day need for urban amenities and facilities? Are the owners of bamboo dwellings, for instance, a part of the mainstream housing sector, having the same rights and privileges as those enjoyed by other property owners? Will they have access to loans for building, improving, renovating or repairing their dwellings? Why do we still hesitate to build a bamboo house for ourselves? Is our policy framework and political resolve in place, to welcome such alternative technologies? It is time we found these answers to these questions, in order to explore the reasons for large-scale nonacceptance, of a technology proven for its worthiness

From among the various alternative materials, bamboo has been the most researched upon for its use as a building material. Yet with all its attributes, and unique qualities, well documented, and certified by experts for its appropriateness and usefulness in its multiple applications in the building industry, it has hardly penetrated the housing market much to talk of, in India. Most examples of bamboo structures use whole bamboo and usually permit a ground floor construction.

Chandra Sabnani, Visvesvaraya National Institute of Technology Nagpur, India, (phone: +91-9890253994; fax: 0712-2801376; e-mail: Chandra_sabnani@hotmail.com).

\section{THE NEED To EXPLORE NON-ACCEPTANCE OF BAMBOO DWELLINGS}

Could the hesitation be because of lack of awareness? Is it due to a simple resistance to adopting an alternative technology? Or does it have a deeper explanation?

Why has it become so easy for conventional housing techniques and materials, to completely wipe out the richness of the deep rooted traditional architecture using mud and bamboo construction, the construction skills for which had been mastered by our fore fathers? Why are the conventional houses selling, despite being unaffordable? Are the traditional construction skills vanishing?

At this rate a wonder material like bamboo is likely to end up in laboratories and never be able to get transferred on to the land. There is hence a clear need to explore the reasons for non-acceptance of bamboo dwellings.

The study that was undertaken aimed at Investigating the Prevalence, Relevance and Appropriateness of bamboo technology for housing in India where both availability of bamboo and construction technology, are not a deterrent factor.

Few of the findings are of relevance to those committed towards working voluntarily through NGOs, on alternative building materials, to make housing affordable for larger sections of society. The follow up on the results could very well culminate into an action research for transforming the attitude of planners, decision and policy makers who could redefine architecture to mean "a people centric technical art form not entirely dedicated to the elite of the society".

The study conveys strong messages to those engaged in Government Departments of Town Planning for a re-look at the housing strategies, the necessity for evolving policy frameworks, in order to incorporate appropriate materials for mass housing.

\section{URBAN DYNAMICS}

An apparent urgency emerges, for addressing issues such as i) The reasons for a rapid increase in houselessness among the Urban Poor ii) The non- convergence of the Nation's Economic objectives and the Physical Planning objectives. The former being focused on creating employment in cities and the latter unable to create housing and related infrastructure to accommodate the migrants gracefully and respectfully. (Fig. 1 shows consistent growth of Urban 
Population) iii) The Physical Planners turning a blind eye even as much as to acknowledging the presence of the first generation Urbanites, the Urban Poor. Parallel mass housing using unconventional materials, becomes unthinkable in such a scenario. iv) When, how and who will ensure that the experiments conducted on the benefits of using unconventional materials and technology across cultures, ever get transformed into a reality? v) When, how and who must ensure that knowledge, skill sets, innovations and best practices, trickle down to the last level of an overly simple and modest dwelling unit designed for those who need them the most i.e. the urban poor ? It is high time; some of these vital issues were resolved!

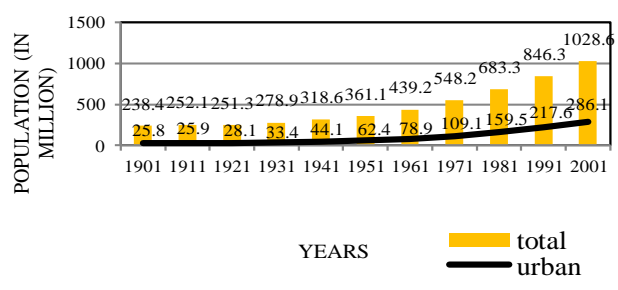

Fig. 1 Share of Urban Population in the Growth of Total Population (Source: Registrar General of India)

\section{THE GENESIS OF DISPARITY AND UNAFFORDABILITY}

In India a "pucca" (permanent) house, owned by an urbanite however modest it may be, sits on a property that constantly appreciates in its value. The dwelling unit provides him with the opportunity for upward mobility even before it has been paid for. The owner can speculate. A house becomes an asset for him. He has all the documents which qualify him to be a part of the formal sector. He can even participate in the commercial speculation of his property which he rightfully and legitimately owns.

Whereas the urban poor build "kuccha houses" (temporary or semi-permanent), on a piece of land, which does not belong to them. Their houses are self - made, out of whatever they can lay their hands on eg.GI sheet, bricks, tarpaulin, plastic sheets during rains, with bricks and stones as weights to prevent such materials from flying in the strong winds. Nothing about these houses is even remotely permanent. With no documents, to establish their ownership, they get excluded from the formal sector. Exclusion makes the informal sector vulnerable to an irrevocable struggle for survival. This scenario demands investigation on identifying alternative and appropriate materials, technology and a set of relevant standards, byelaws and policy frameworks to provide affordable dwellings.

\section{BAMBOO QuALities At A GLANCE}

It is light in weight. It offers a sustainable solution for construction. Due to its regenerating quality it falls under the category of being a renewable resource. It has high tensile strength. And that most of the demerits of bamboo construction can be countered.

To improve durability which is perceived as the biggest drawback, simple precautions of selecting appropriate Species, harvesting time- cutting methods, preventing water from collecting over the node during rains, right age at which bamboo is cut, seasoning air drying or kiln drying, chemical treatment etc. can increase the life of bamboo.

The intervention of appropriate construction technology, to increase the durability of bamboo structures is possible by protecting them. Deep eaves for protection from rain, and a similar protection at foundation and plinth, can go a long way, in increasing the durability of a bamboo structure.

\section{URBAN POOR AND HOUSELESSNESS}

Building new dwelling units for the urban poor is at a pace, far behind that at which the urban population grows. (Fig. 2). This results in: Mass scale houselessness, Self erected temporary unauthorized shanties, usually unfit for human habitation.

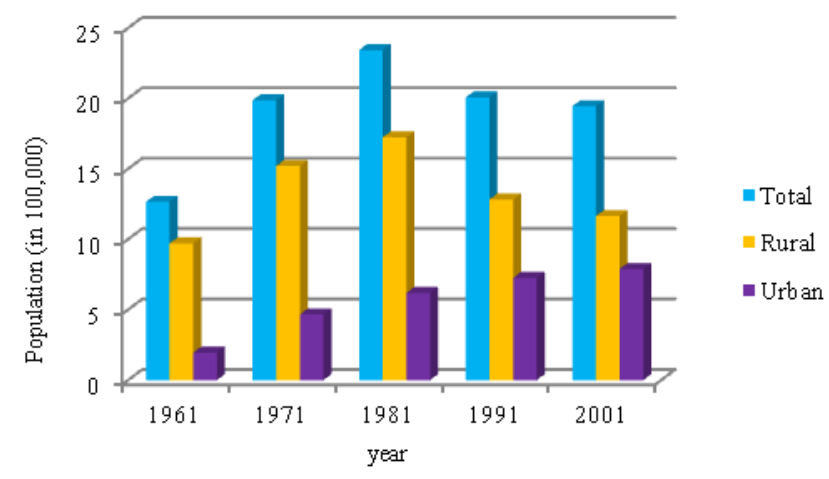

Fig. 2 Houseless Population

The fact that the Urban Housing consists of "kuccha houses" (temporary), "semi pucca" (semi-permanent), and "Pucca houses" (permanent), and two out of the three categories put together clearly contribute towards houselessness, a tentative hypothesis can thus be framed.

\section{GROWTH OF SLUMS}

A migrant who comes to the city initially lives in a temporary shelter. Semi permanence/temporary state of housing by way of "semi pucca / kuccha" dwelling units found in slums and squatter settlements, is a phenomenon associated with the urban poor. Fig.2 represents the share of urban population, in the growth of total population. Urban houselessness is a function of urban population. It grows irrespective of the total population.

The urban poor are the migrants in batches who settle in self erected shanties meant to be temporary. These may be "kuccha" or "semi pucca." This shelter gradually evolves and takes a permanent shape. The rate of evolution from 
"kuccha to pucca" is dependent on the economic stability offered by the city. A prolonged reception by the city could compel the migrant to stay in a "kuccha/semi pucca" house for a very long period of time, to the tune of 2-3 decades.

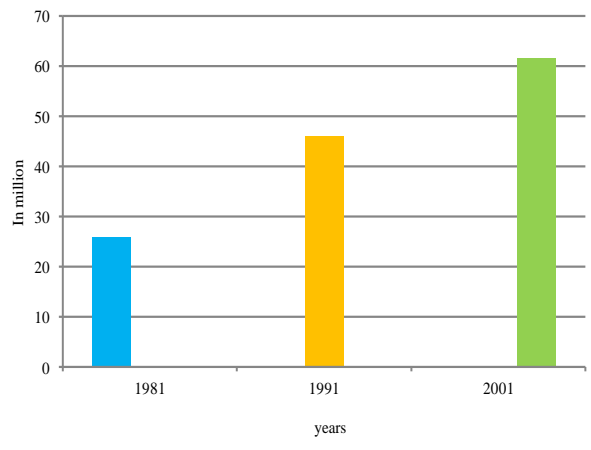

Fig.3 Growth of Slums

(Source: Annual Report 2006-07, M.O.H.U.P.A)

\section{A New Segment Of Housing Needed To MeEt ThIS ChaLLENGE}

The Slum house and /or squatter or the temporary shanty is not value less. (Fig. 3) Improvement of slum housing in urban areas can contribute towards increasing the housing stock. Even the initial basic temporary dwelling unit has the potential to be a part of the housing stock. Making it durable and permanent through intervention would allow it to remain a substantially significant part of the housing stock, for a longer duration, thereby decreasing the absolute figures of houseless population at any given point of time. This may result in fairly safe and structurally stable houses for the migrant who has an additional burden to coexist in an alien urban environment. For cost reduction, by replacing building components and materials (Fig.4 \& 5) affordability can be increased.

Alternative materials for superstructure, roofs, doors and windows alone can account for a cost reduction of $40 \%$.

\section{AFFORDABILITY VS PRIORITIES}

The question of affordability is uppermost, and is perhaps the prime reason for him to get into a permanent battle for survival. At the same time a substandard house can be very demanding in terms of time, energy and money for its maintenance. At very low daily incomes, emergent priorities, and erratic non-budgeted expenditure patterns, could lead to a skewed result, making affordability a highly sensitive variable rather than a constant indicator.

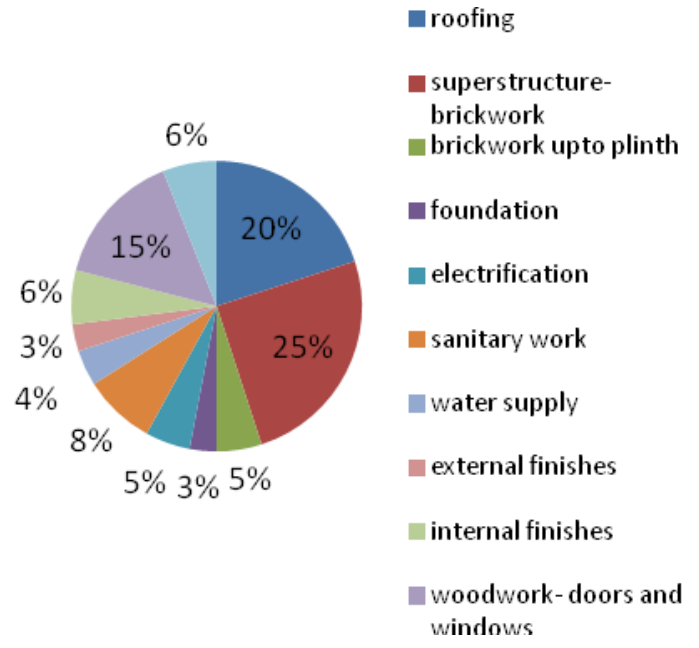

Fig.4 Cost Reduction by Construction Elements

Approximate Breakup of total Construction cost for different elements of building

Bamboo being one of the cheaper materials plays an important role in providing the migrant a shelter; of course in combination with other materials. This is especially true for urban areas close to bamboo growing regions.

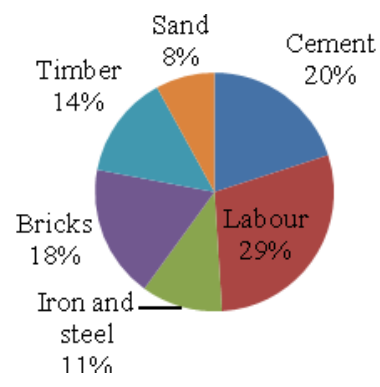

Fig.5 Cost Reduction by Replacing Building Materials

An approximate break-up of total construction cost for materials and labour.

By increasing the share of bamboo for constructing walls, floors, roofs etc. these houses can be designed for a longer life, improved quality, and low maintenance thus prolonging the urgency to move from " semi pucca to pucca" dwelling. It can reduce the cost tremendously, on account of its durability which makes it qualified enough to be a welcome addition to the housing stock, for a longer duration, minimizing the houselessness at any given point of time.

(Fig.5) Bamboo in combination with other alternative materials if used to replace the superstructure, roofing, doors and windows alone, can account for a cost reduction of up to $40 \%$. Similarly, substituting bricks, cement, steel and timber alone, can account for a cost reduction of up to $40 \%$. 
Substituting bricks, cement, steel and timber alone can account for a cost reduction of up to $40 \%$

As and when the migrant, who has by now graduated to being a first generation Urbanite, decides to make a "pucca house, " he has the option to move out to another location and sell/rent the original house to the next generation migrant. This would save the cost, effort and time required to demolish and reconstruct. The new migrant has a ready house, saving him the struggle on multiple fronts, for sustenance.

The act of demolition of any dwelling unit, habitable or not, is a sensitive issue socially as well as economically speaking, and above all wasteful, in these times when resources are meager. Any demolition accelerates houselessness, hence, for the time being stands undesirable. The self constructed shanty offers temporary yet an "assured" shelter. Houselessness would lead to permanent hopelessness. The Shanty is thus not value less!

For whatever reasons, if history has revealed that houselessness has been increasing, then it becomes necessary to examine the phenomenon that creates it, in order to prioritize the intervention before formulating a strategy.

\section{THE PHENOMENON}

A batch of migrants flocks into a developing city, in search of odd jobs to begin with. The dwelling unit is secondary for each of them. He needs a job more urgently. So he builds a shanty with waste materials, or at the most some GI sheets, packaging wood, cartons, tarpaulins, plastic sheets, with bricks and heavy stones on the roof to prevent it from flying due to strong winds. He may use Bamboo as a structural member if it is easily available or may resort to a few" ballis" (shuttering props out of wood.)

This would be his home for an indefinite period of time, but as is obvious, is hardly a house suitable for dignified living. Leave alone dignity, it is not even safe or structurally sound. Constructed as an encroachment on a piece land it is a constant threat to him for evacuation, mostly without any alternative support system. His financial insecurity and uncertainty leads him to a dead end .One of the many reasons include possessing a house which is "temporary" and therefore not qualified for loans towards home improvement or construction. His "unauthorized" status adds to the disqualification. He has by default, been compelled to join the informal sector, the one that is denied all the privileges, incentives and benefits of urban living. He is an urban poor, having the worst of both the worlds, the urban and the rural.

The pucca houses have failed to meet the housing shortage especially after 2001, when it has more than doubled (Fig.6) The contribution of the semi pucca and the kuccha houses towards fulfilling the housing demand is marginal.

There does not seem to be much effort in using the kuccha and semi pucca houses as a means to increase the housing stock.

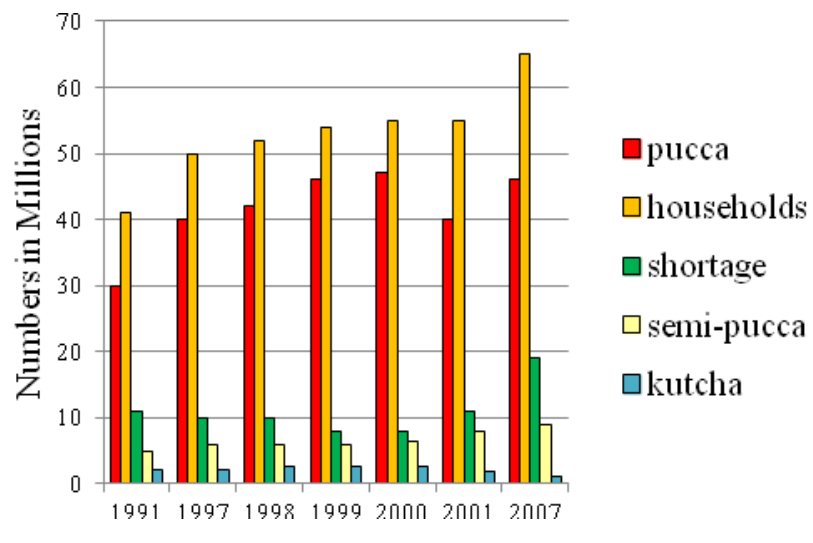

Fig.6 Housing stocks, households and housing shortage

The research hinges itself on the fact that a large potential segment of housing is considered as being valueless. This can be traced through right from the definition of a "pucca house", as per the census to the criteria listed for housing finance by funding agencies, to the National policies, to the Building Byelaws, to the Development Control Rules and finally to the psyche of the inhabitants for whom a house can only mean a pucca house which is out of steel, cement, bricks, and concrete, glass and timber, or an RCC framed Structure and RCC slab for a roof.

It focuses on the experiments and innovations which centre on countering the limitations and exploiting the potential for the construction of dwelling units in Urban Areas.

\section{SEeKING Global ExAmPles AND SOlutions}

An attempt has been made to identify such places in the bamboo growing regions of the world where constant experiments with bamboo either whole bamboo or engineered have been successfully conducted. Where, some of the limitations have been partially or fully countered, for the purposes of construction.

Where the Potential and Possibilities have been partially or fully harnessed or where Policies have been framed to reach out and declare it as a material at par with other mainstream housing materials, for the urban poor to provide easy access to loans / insurance etc

Places where governance, political will, legislative and techno- financial environment has been created to encourage the use of bamboo for construction purposes, and attempts have been made to elevate a bamboo dwelling unit to the status of a capital asset having an appreciating property value.

Legislative and techno-financial environment would essentially mean, formulation of a set of standards for the use of bamboo, along with guidelines and regulatory measures, integrated into the National building Code as special specific byelaws for bamboo growing regions. 


\section{REFLECTIONS}

\section{A. Create a Parallel Construction Industry}

One, few or the combination of all the measures could transform bamboo into an appropriate material for all the Key building components. It can be considered as a material that can partially replace the key building materials which add up to form a major part of the cost. A material technology that could make architectural design fairly functional, durable, safe, green, climate responsive, affordable and socially acceptable

Measures need to be taken to treat bamboo technically up to such a level of fineness, that it gets qualified as a structurally safe and durable material for construction, enough to attract bankers financiers and other funding agencies, rendering it as an appropriate material for mass housing. A material technology that could redefine architectural design thus making room for a totally new segment and variant called parallel housing. It is only then that the technical innovations can find a market even among the Urban Poor, residing close to bamboo producing regions.

Measures need to be evolved to formulate techno - financial models or system mechanisms which should operationally be able to transform an architecturally designed bamboo house into an easily accessible commodity which can be treated as an asset or an investment, attracting speculation for its value appreciation.

It could be visualized as a material which shall simultaneously create a parallel construction Industry, while also being commercially beneficial for the owner. This would encourage investment in a bamboo house. This phenomenon is already in existence among the urban poor, but the properties in most cases are shanties, with a very short life span, hence the values do not appreciate in consonance with the other pucca properties around the same area. Hence the commodity continues to remain at unattractive levels of commercial interest.

At this stage, when measures have already been evolved for evaluating, and establishing the application and usefulness of bamboo as an appropriate structural material, it now becomes necessary to review global examples, where the Policies, have led to, an increase, in the efficiency in construction and distribution, of bamboo dwelling Units.

As such it becomes imperative to formulate a set of standards for the use of bamboo as a structural material, along with guidelines and regulatory measures, integrated into the National building Code as special specific byelaws for bamboo growing regions.

\section{B. Selection and Looping}

In order to arrive at a standard package several looped packages linking, Limitations, Potentials and Possibilities, Measures, Policies and the Legislative-techno-financial models are expected to be generated, through experiences, developments, innovative break-through and traditional practices. These may form consistent, inter-dependent circuits. If on examining each of the loops, a reasonably workable package is identified then a complete strategy can be evolved to tie up the administrative and organizational set-up, in order to reach out to the Urban Poor. Bamboo can then be used for construction of houses for the urban poor residing close to bamboo producing regions, thus adding to the national housing stock, and reducing the houselessness in the country by way of providing low cost eco friendly solutions.

\section{Support System Required for Bamboo Regions}

The research in the area of identifying technical corrective measures is only a small part of the exercise, to ensure the delivery and distribution of affordable housing, using a renewable material such as bamboo, so as to reach the target group.

Merely discovering a technology is not enough to ensure access to affordable housing. An equally rigorous follow-up exercise to have the systems in place and to evolve standards, codes, byelaws and charters will be required.

A parallel research on financial management evolving soft criteria for offering cheap loans, subsidies and formulating social security measures to extend over the right to modest housing and humane living environment for the poor under the provisions of Article 43 which currently focuses only on just and humane environment for work.

Insurance facility against fire, theft, death along with medical insurance to promise financial security will have to be dovetailed to the package of benefits and privileges legitimately acquired by a citizen. The Policies therefore shall have to be thoughtfully framed in order to embrace the phenomenon of migration and accommodate them willingly, instead of allowing them to stay informally on unauthorized patches of land within the city disrupting the rhythm of the city, through overloading the infrastructure which was never meant for them.

Simultaneously the administration wings created especially for the owners of low cost houses out of Bamboo, with special provision for smooth and fast clearance of applications for building bamboo houses, and if possible even providing an incentive package.

The monitoring and control network, the training institutes to provide parallel hands-on education, and the active involvement of voluntary agencies, NGOs, grass-root level workers, and elected representatives, sanitation engineers along with self help groups, all shall have to work in coordination. Funding agencies and research labs providing innovations, and break-through in the bamboo construction field. Construction of architectural live models, for active promotions and display, to attract those who are willing to experiment with construction of bamboo houses, may have to be an integral part of the program. Capacity building measures must precede the actual construction boom for bamboo housing in order to cater to the demands of mass housing. Building components, partially replaced with bamboo shall be used to arrive at permutations and combinations, for creating a variety of architectural designs, which would also 
provide choices for selecting the one that would best suit the budget, and monthly installments for the repayment of loans.

Last but not the least is the political will and the correction in the census definition of a pucca house, for the inclusion of composite bamboo housing to make it easy for such house owners to treat it as an asset through-out its life span.

\section{CONCLUSIONS}

Despite the fact that Bamboo has known qualities and an established reputation of being a wonder building material (eco friendly, regenerative, high tensile strength, low cost etc.), it has not penetrated the urban housing market, nor has it become a popular building material even among the Urban Poor.

It is quite surprising that bamboo, which has been researched upon through ages by scientists from all over the world, endorsed as one of the most eco-friendly, sustainable building materials, could never become a natural choice for constructing houses for the urban houseless.

Bamboo houses are not preferred and as such do not seem to be socially accepted. It is ironical that people prefer to remain houseless in the hope of being able to construct lafford a conventional "permanent" house rather than to construct one out of bamboo, especially in urban areas. The other understanding could be that for this segment of people, even a cheap bamboo house is beyond their paying capacity and/or purchasing power.

Given that there is a history of an ever increasing housing shortage, commensurate with the rising un- affordability, the dependence of convenience, on conventional building materials, like cement steel concrete, throws the issue open to academic criticism.

The housing sector cannot afford to ignore alternative materials and techniques which promise to offer a sense of permanence, affordability, reasonably dignified presence in the city, humanly habitable, when combined with basic urban infrastructural facilities.

A new segment of housing is needed to meet this challenge. A fresh look at the age-old materials and technologies, repackaged to blend with the current socio-cultural environment, and the demands of the time, is inevitable.

A material like bamboo brings with it all the well known limitations. Research energies, the world over have been focusing on countering these limitations. Once these are countered, bamboo is rendered with properties that make it highly appropriate for tropical climate. Give it an English hat and boots, (Deep eaves and plinth protection) and it becomes suitable even for driving rains. For seismic regions it is reputed to cause the least damage to life and property. Being light in weight foundation costs are saved tremendously.

Hence the question is not just that of "Why not bamboo?" but remains that of "how to reach out to promote it".

If bamboo technology is made convenient to handle, promoted along with standards, codes and bylaws, tied up with the legal and the financial machinery, then the entire package put together could go a long way in eliminating houselessness. Once a gateway is created for bamboo, all other alternative materials and technology would follow.

Prof. Falade, who experimented with Bamboo Reinforced Concrete, proved that it is a reinforcement which can be, designed in just the same way as Steel reinforced concrete with a few extra precautions. This and many other findings can make bamboo frog leap into the mainstream market and offer great relief to the houseless and the very poor.

\section{ACKNOWLEDGMENT}

Author would like to thank Dr. Narendra Choudhary, Director, Visvesvaraya National Institute of Technology, Nagpur and Dr. Animesh Chatterjee (Dean - Research and Consultancy, Professor at the Department of Mechanical Engineering, V.N.I.T.) for providing me the opportunity to write and publish this paper.

\section{REFERENCES}

[1] F. Falade and T. A. I. Akeju (1997). 'The Potential of Bamboo as Construction Material' Fourth Int. Congress on Structural Engineering Analysis and Modeling (SEAM 4) - Ghana 9-11 September, 1997, pp. 447-460.

[2] Bamboo "The gift of the Gods by Oscar Hindalgo Lopez "pp $14-47$

[3] T. A. I. Akeju and F. Falade 'Utilization of Bamboo as Reinforcement in Concrete for Low-cost Housing', Proceedings, International Conference on Structural Engineering, Mechanics and Computation, Cape Town, South Africa, 2-4 April 2001, pp 1463-1470.

[4] F. Falade and T. A. I. Akeju 'The Behaviour and Analysis of Bamboo Reinforced Concrete under Flexural Loading', Proc. Fifth International Conference on Structural

[5] F. Falade and T. A. I. Akeju 'Structural Design and Economy of Bamboo Reinforced Concrete Beams', Proc. Fifth International Conference on Structural Engineering Analysis and Modeling, (SEAM Engineers' Centre, Accra, Ghana, March, 2002, pp 215-228.

[6] T. A. I. Akeju "Utilization of bamboo as reinforcement in concrete for low-cost housing. Flexural Behaviour of Bamboo Reinforced Concrete Slabs. International Journal of Engineering, international Center for Advanced Studies, West Bengal, India. Vol. 2, No. 2, p169- 182 